\section{Vincent van Gogh (1853-1890)}

\section{Der Künstler und die Kopien}

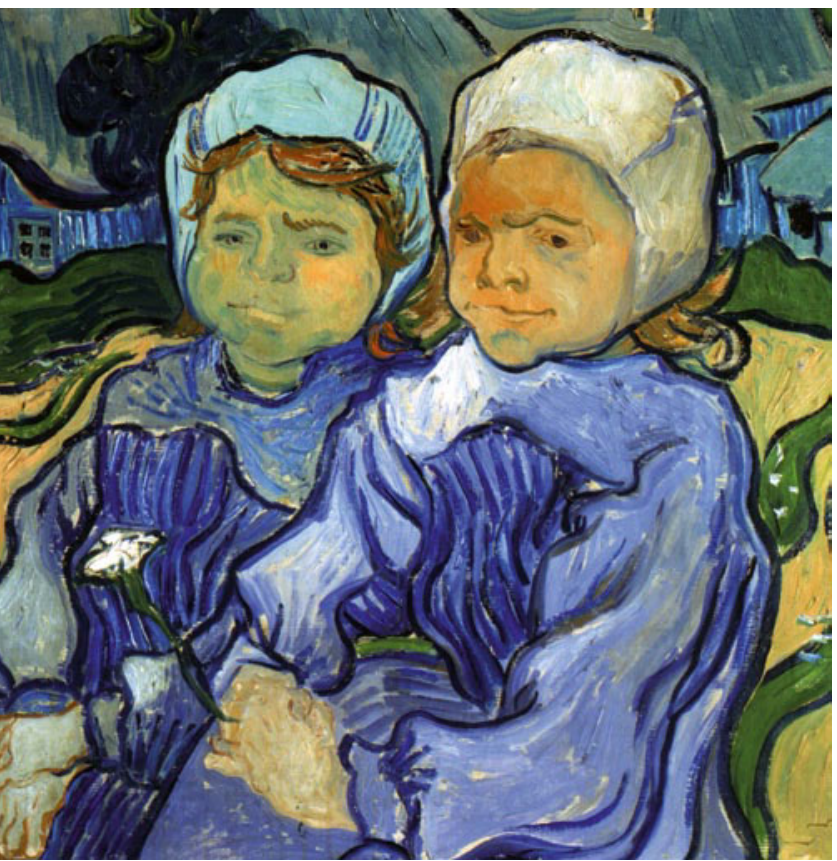

Das Jahr 1890 sollte Vincent

van Goghs letztes sein. Er

lebte in Auvers-sur-Oise in

der Nähe seines Arztes

Dr. Paul Gachet. In dieser

sehr kreativen Zeit entstand

auch das Titelbild dieser

Ausgabe. Nach van Goghs

Tod lies Gachet dieses und

viele weitere Bilder kopie-

ren.

Vincent van Gogh

„Zwei Kinder“ (1890)

$\mathrm{V}$ incent van Gogh hat nur wenige Kinderbilder gemalt. Eines der schönsten Kindermotive überhaupt ist für mich sein Gemälde „Erste Schritte" (1890), das bereits in Ausgabe 2/2005 vorgestellt wurde. Von „Zwei Kinder" gibt es zwei, eigentlich sogar drei Bilder. Eines ist im Musée d'Orsay in Paris zu sehen, eine Kopie befindet sich in einer privaten Sammlung in Zürich, das dritte ist ebenalls in Privatbesitz. Die Kleidung der beiden Kinder zeigen die für van Gogh typischen geschwungenen kraftvollen vorwiegend blauen Farben mit sichtbaren Pinselzügen, während die blassen grünlich-gelben Gesichter nur angedeutet werden und unvollständig gemalt wirken. Im Hintergrund sind die Fenster von kleinen Häusern sichtbar.

\section{Die letzten Monate}

Vincent van Gogh hatte sich nach einem epileptischen Anfall im Mai 1890 in das in der Nähe von Paris gelegene Dorf Auverssur-Oise zurückgezogen, um einerseits in der Nähe seines Arztes Dr. Paul Gachet zu
Gachet junior wiederum vermachte vor seinem Tod dem Staat eine große Zahl von Originalen und Kopien von VanGogh-Bildern, die von ihm, seinem Vater und eben von Blanche Derousse angefertigt worden waren. In der Ausstellung des Musée d'Orsay „Ein Freund von Cézanne und van Gogh - Dr. Gachet" im Jahre 1999 befand sich auch das Aquarell „Zwei Kinder". Das Original dieses von van Gogh in Auvers gemalten Bildes sei für eine Ausstellung in einen zu kleinen Rahmen gezwängt worden, schreibt Hanspeter Born in der „Weltwoche“ (8/2008), was zur Folge gehabt hätte, dass durch die Faltung der Bildränder die Finger des einen der beiden Kinder „abgeschnitten“ worden seien. Ein Foto dieses Bildes habe Dr. Gachet bekommen. Dieses wiederum habe dann Blanche Deroussse kopiert, ohne das Original gesehen zu haben. Die immer noch als Van-Gogh-Zweitfassung im Musée d'Orsay ausgestellten „Zwei Kinder" sei in Wirklichkeit eine Kopie von Blanche Derousse.

\section{Künstler beginnen mit Kopien}

Forschungen zeigen immer wieder, dass vermeintliche Originale großer Maler in Wahrheit Kopien sind oder anderen Malern oder Schülern zugeordnet werden. Selbst Fachleute haben sich mit ihren Interpretationen getäuscht und können sich weiterhin durch das Hineininterpretieren von besonderen Bildqualitäten irren. Für die betroffenen Museen bedeutet eine aufgedeckte Fälschung einen herben Verlust.

Mit dem Kopieren von Gemälden großer Meister haben fast alle bedeutenden Maler begonnen. Sie haben dazu häufig während ihrer Ausbildung Italien und vor allem Paris besucht. Auch Vincent van Gogh, aufgewachsen in dem niederländischen Dorf Groot-Zundern, besuchte schon 1869 als 14-Jähriger in Den Haag die Museen, 1873 den Louvre in Paris und begeisterte sich für Camille Corot und die niederländischen Maler des 17. Jahrhunderts. 1880 kopierte er in Paris Werke von Jean-Francoís Millet. Mit dem Studium an der Kunstakademie in Brüssel entschloss er sich 1880 endgültig, Maler zu werden, nachdem er sich zuvor zu einer religiösen Laufbahn berufen gefühlt hatte.

Dr. Joachim Gunkel, Dannewerk 